\title{
All in the Family
}

\author{
Christian G. Wolff, M.D.
}

Monday

TS, a 31-year-old woman, came to see me today because on numerous occasions she has had to pull her car onto the shoulder to avoid passing out. These episodes occur randomly and infrequently, but they have her significantly troubled. A brief review of her family history reveals that I also treat her sister and her mother-one for bipolar disorder (mild and well controlled with medications), the other for severe depression (requiring psychiatric consultation and hospitalization). With each episode, her anxieties surrounding her family history have escalated. I have begun her on treatment with paroxetine and arranged for her to visit with a trusted social worker who does a lot of work with patients with panic disorder. I'm curious to follow her progress. I, too, have anxieties that she may have some unmasked pathology. I understand bipolar patients have panic attacks about one third of the time. With her family history, I will be vigilant.

\section{Tuesday}

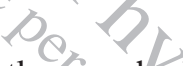

BG is a 61-year-old gentleman who is new to my practice, but I have been caring for his son, daughter-in-law, and 2 grandchildren for the past 3 years. $\mathrm{BG}$ is a retired policeman who 9 months ago moved to the area with his wife after 30 years at their old home. His complaint was 2-fold: he couldn't "kick the blues" now for 7 months, and he hadn't had a good night's sleep for as long as he could remember. He works part-time as a self-employed consultant and exercises fervently. These things, along with spending time with grandchildren, he used to enjoy, but now they had become chøres. He âlso had begun to have "fright attacks" at night as he recalled events from his career in law enforcement.

Today, I saw him in follow-up after starting mirtazapine, and he has outstanding results. All of his symptoms are significantly improved, and he attributes his increased appetite to the renewed vigor of his exercise regimen (his weight is stable). Now, though, his late-night buddies from Internet poker are sending him e-mails complaining that he has abandoned them. I guess you can't win them all.

\section{Wednesday}

Today I received a letter from a former patient who has moved out of state and has not been able to establish a comfortable relationship with a new physician at her new location several time zones away. She asks for advice with current problems. Yikes! That is challenging enough in the exam room, let alone long distance. I tried to give good general advice and asked her to consult 
the residency director of her local family medicine program. I hope she can obtain a referral to a local family physician who is comfortable in the care of mood disorders. Any suggestions for coordinating the transfer of care for patients like her?

\section{Thursday}

YD is a young mother with a 2-month-old daughter. She is clearly distraught over her child's crying and is at wit's end. The baby is adorable in the office-cooing and cherubic. Exam of the child is entirely normal. Mom is another story. She has not been sleeping, and she, who was so looking forward to motherhood, actually states that she "hates it" and feels significant guilt that she may be a poor mother. On review, she had severe premenstrual dysphoric disorder symptoms prior to conception. What began with a well-child check ended with mom getting a prescription for fluoxetine. At least she didn't have to get 4 immunizations!

Friday

Following up on the maternal issues, $\mathrm{GH}$ is in today for treatment of anserine bursitis, when she, in typical "oh, by the way" fashion, asks about stopping her fluoxetine in anticipation of trying to conceive. She has had severe recurrence of depression on 2 separate occasions upon discontinuation of the medication and, justifiably, is concerned about discontinuing the medication now. While injecting her pes, I discussed with her the data that show the relative safety of fluoxetine during pregnancy, and we considered the pros and cons of continued medical therapy. Giving her the facts, though, I emphasized that it was an educated decision that she had to make herself. I'm not sure if she was pleased because of our conversation or because her knee had ceased hurting. Anyway, she was pleased all the same.

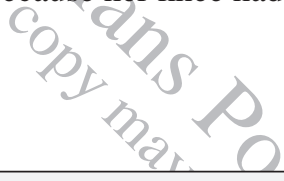

Editor's note: Dr. Wolff is a board-certified family physician in private practice in Huntersville/Davidson, North Carolina. He finished his family practice residency in 1997. He has graciously consented to share stories from the trenches of primary care. While his practice diary is taken from actual patient encounters, the reader should be aware that some medication references may represent off-label uses. We at the Companion are certain that these vignettes will inform, entertain, challenge, and stimulate our readers in their effort to address behavioral issues in the everyday practice of medicine. 